\title{
Noise Reduction Using Active Vibration Control Methods in CAD/CAM Dental Milling Machines
}

\author{
Eun-Sung Song ${ }^{1}\left(\mathbb{D}\right.$, Young-Jun Lim ${ }^{2, *} \mathbb{D}$, Bongju Kim ${ }^{1}\left(\mathbb{D}\right.$ and Jeffery Sungjae Mun ${ }^{3}$ \\ 1 Clinical Translational Research Center for Dental Science, Seoul National University Dental Hospital, \\ Seoul 03080, Korea; songeunsung@gmail.com (E.-S.S.); bjkim016@gmail.com (B.K.) \\ 2 Department of Prosthodontics and Dental Research Institute, School of Dentistry, Seoul National University, \\ Seoul 03080, Korea \\ 3 Department of Biology, Swarthmore College, Swarthmore, PA 19081, USA; jmun1@swarthmore.edu \\ * Correspondence: limdds@snu.ac.kr; Tel.: +82-02-2072-2040
}

Received: 28 February 2019; Accepted: 8 April 2019; Published: 12 April 2019

\begin{abstract}
Used in close proximity to dental practitioners, dental tools and devices, such as hand pieces, have been a possible risk factor to hearing loss due to the noises they produce. Recently, additional technologies such as CAD/CAM (Computer Aided Design/Computer Aided Manufacturing) milling machines have been used in the dental environment and have emerged as a new contributing noise source. This has created an issue in fostering a pleasant hospital environment. Currently, because of issues with installing and manufacturing noise-reducing products, the technology is impractical and insufficient relative to its costly nature. In this experiment, in order to create a safe working environment, we hoped to analyze the noise produced and determine a practical method to attenuate the noises coming from CAD/CAM dental milling machines. In this research, the cause for a noise and the noise characteristics were analyzed by observing and measuring the sound from a milling machine and the possibility of reducing noise in an experimental setting was examined using a noise recorded from a real milling machine. Since a milling machine generates noise mainly due to vibration of the dust collector, the possibility of reducing noise was examined by controlling vibration. This study was conducted to understand the cause for noise from the milling machine and verify the possibility of improving noise by a tactile transducer.
\end{abstract}

Keywords: noise reduction; active vibration control; tactile transducer; anti-vibration; dental milling machine

\section{Introduction}

Workplace noise exposure directly influences the health of workers. Dental professionals are exposed to high levels of noise while working in dental clinics or laboratories. Both the intensity and long duration of noise from dental work environments are known to contribute to hearing loss [1].

Recent studies have assessed noise exposure and hearing problems in dental practices on students from a dental college located in the United Arab Emirates (UAE); about 80\% of students experienced some noise, $54 \%$ reported that they have hearing problems, and $10 \%$ reported hearing loss. The study recommended the use of sound absorbing materials in the construction of dental offices and laboratories in order to reduce the noise levels [2]. Dental professionals who regularly used high-speed hand pieces had worse hearing than those who did not use these hand pieces [3].

In addition to the existing noises, studies by Fabry, Gijbels et al. and Messano and Petti indicate that the introduction of new technologies such as three-dimensional (3D) CAD/CAM milling machines have contributed to the existing noise source of dental clinics and laboratories, causing greater than expected hearing loss in dental professionals than before $[4,5]$. 
In general, there are two ways to reduce environmental noise: passive and active. The passive method uses techniques such as enclosures, barriers, and silencers [6]. While these passive noise control techniques can help facilitate noise control of mid and high frequencies, they are inefficient and costly at lower frequencies. The active method uses an active noise control (ANC) system to cancel the unwanted noise based on the principle of superposition [7]. Specifically, identical amplitude and antiphase anti-noise is created and actively integrated with the first noise, thereby triggering the elimination of both noises [8]. Several studies were published on the application of ANC methods (such as active noise canceling for headphones using a hybrid structure, active noise control in headsets by using a low-cost microcontroller, a low-power broad-bandwidth noise cancellation for in-ear headphones, adaptive feedback active noise control headset and sound quality of the machine) [9-15]. Although various problems are raised and relevant studies are constantly increasing to address noise problems, studies on noise in the dental treatment room including the medical industry are inadequate. In addition, efficient production methods considering costs and methods are needed to apply this noise elimination method into machines aiming for commercialization [12,14]. We recently investigated a more effective approach to noise reduction in the CAD/CAM milling machine using tactile transducers to produce tactile sound. This study was designed to determine the main noise source generated from CAD/CAM milling machines installed in dental clinics or the laboratory, and to create a pleasant clinic environment by applying a noise reduction method.

\section{Methodology}

The first step to reducing the noises produced by CAD/CAM milling machines was through an investigation of the causes and sources of noise level through experimentation in a closed environment. After determining the cause and location of the noise source, we identified the main target area for noise reduction. Using the information on the targeted area, a noise control method was proposed. A block diagram description of the method is shown in Figure 1.

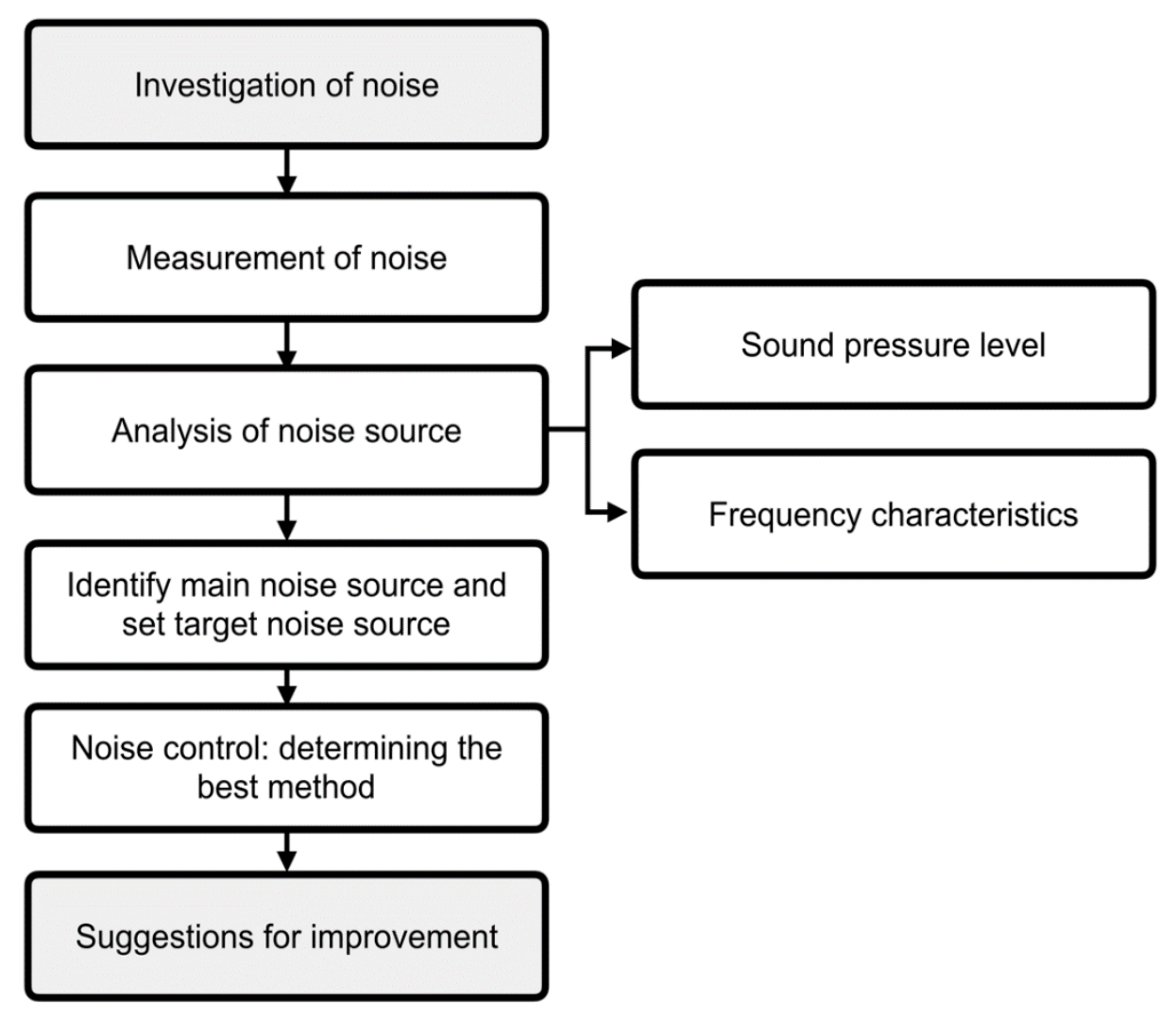

Figure 1. Noise improvement process. 
Dental CAD/CAM milling machines can be categorized as drying or wetting type depending on the use of water during the milling process. A more suitable method is determined by considering the type of material and milling process used. The wet type does not require a dust collector because it uses water. On the other hand, the drying type requires a dust collector because it produces dust, but the dust collector causes noise. Therefore, the process conditions were classified as follows and the investigation methods of milling machine noise were selected accordingly (Table 1).

Table 1. Investigation of milling machine noise.

\begin{tabular}{lcc}
\hline Process Conditions & Use Conditions & Investigation Methods \\
\hline Dry milling process & Use of dust collector & Vibration and noise level \\
Wet milling process & No use of dust collector & Noise level \\
\hline
\end{tabular}

\subsection{Equipment}

The CAMeleon CS®CAD/CAM milling machine (NeoBiotech, Seoul, Korea) was employed to obtain all test results presented in this study (Figure 2). The noise level was measured while the machine was running with a diamond bur cutting a zirconia block.

The noise was analyzed by sound pressure level, frequency spectrum and vibration. The sound level intensity was measured with a Digital Sound Level Meter (Lutron Sl-4013®, Lutron, Taipei, Taiwan) by using the $\mathrm{dB}$ scale. The frequency spectrum of noise was investigated by a half-inch microphone (ECM8000®, Behringer, Willich, Germany). The vibration frequency of noise was analyzed by a Vibration Tester (AV-160B $®$, Vetus, Guangdong, China). The equipment used for noise level evaluation are presented in Table 2.

Table 2. Equipment list used for noise level evaluation.

\begin{tabular}{cccc}
\hline Equipment & Microphone & Sound Level Meter & Vibration Tester \\
\hline \multirow{2}{*}{ Company/Model } & Behringer & Lutron & Vetus \\
& ECM8000 (USA) & Sl-4013 (Taiwan) & A-160B (China) \\
Specifications & Frequency range: & Measurement range: & Frequency range: $10 \mathrm{~Hz}-1 \mathrm{kHz}$. \\
\hline
\end{tabular}

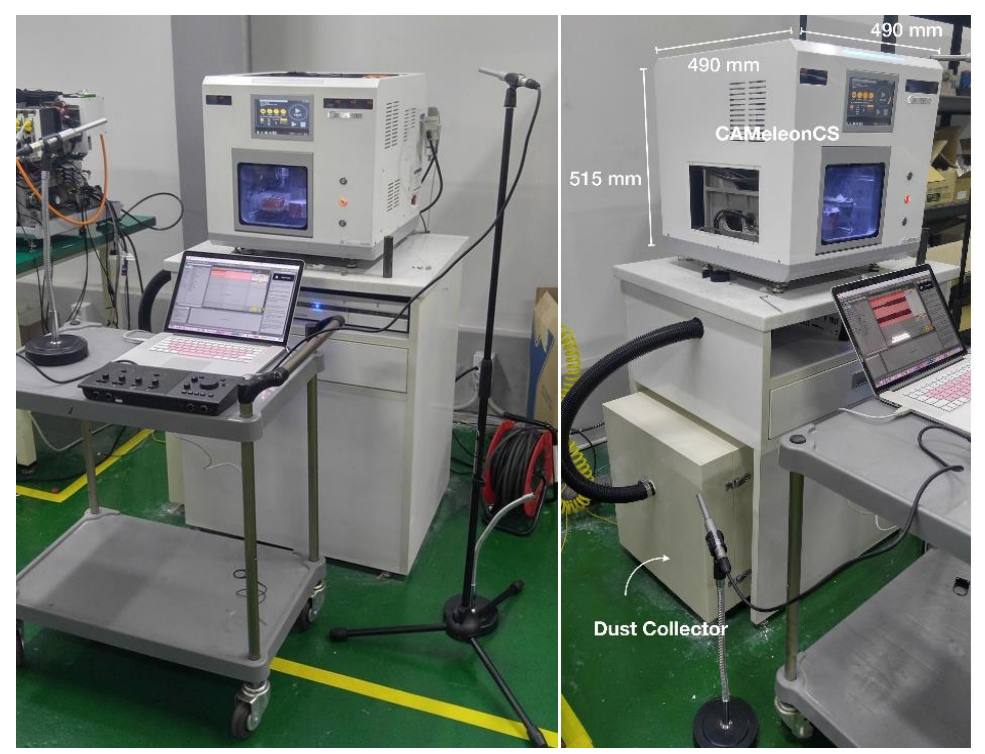

Figure 2. Equipment used to measure and record; noise dust collector and milling machines (CAMeleon CS®). 


\subsection{Noise Survey Method}

To determine the cause and location of the noise, the sound level intensity was measured with a Digital Sound Level Meter. Noise investigation can be conducted in various aspects for hearing loss, talking disorders, noisiness, and improving noise. This study was carried out for investigating noise to identify the noise source in order to improve noise. Measurement location and measuring methods were therefore selected as comparatively easier ways to compare test results, not to measure the absolute sound level serving as the criterion of hearing loss or noisiness, but to identify locations of noise source and causes. Three measuring points (front, left, and right) were selected and measured in an appropriate measuring perspective to identify the sound causes and locations of milling machines. The noise meter repeatedly measured three times per 10 seconds from $1.2 \mathrm{~m}$ above the ground. The place of highest noise level was chosen as a target noise source. The measurement locations were held constant during the experiment as shown in Figure 3.

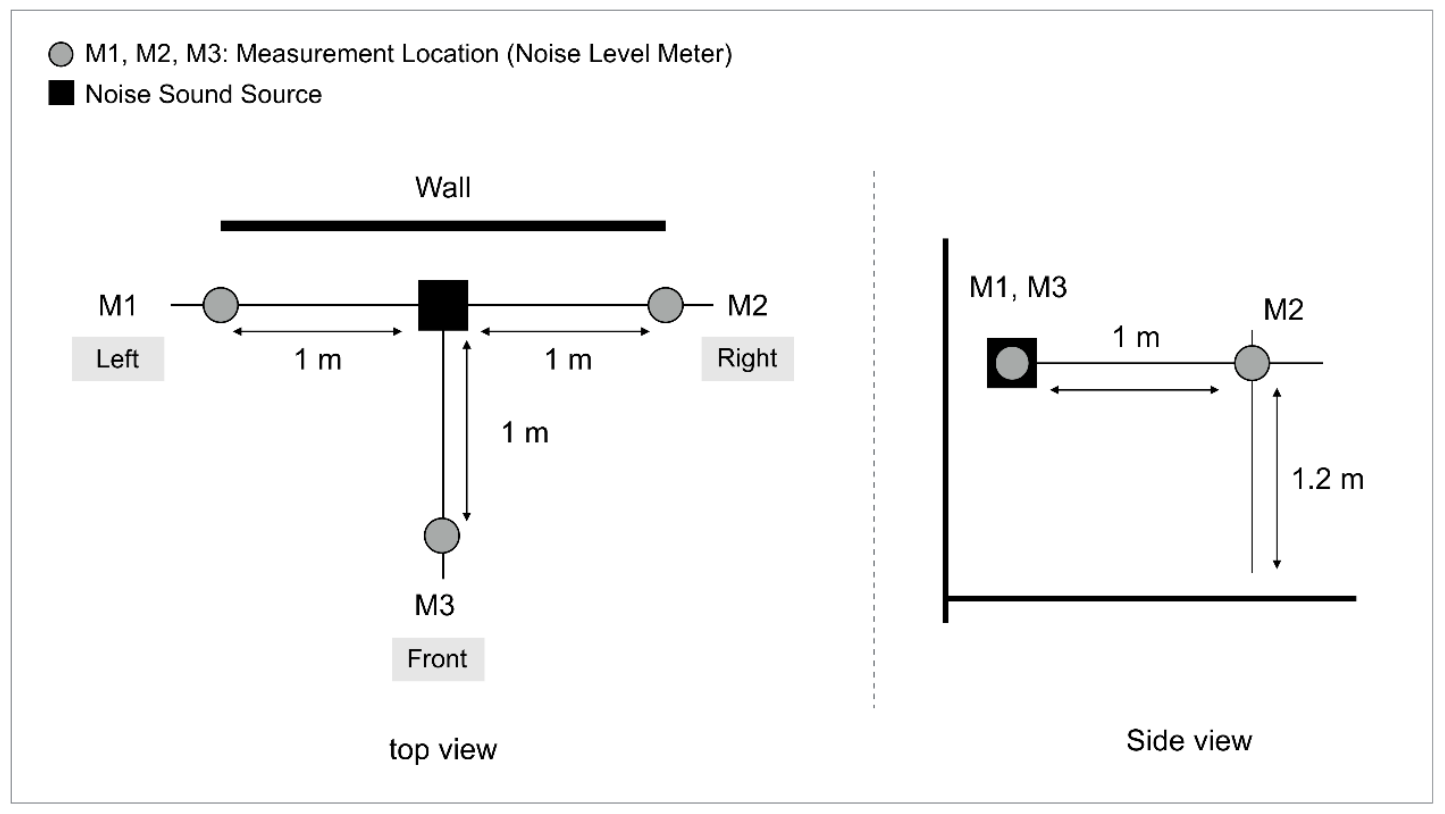

Figure 3. Experimental arrangement for measurement location.

The determination of the mechanical vibration and acoustic noise produced by the dust collector system of the milling machine consists of two steps. Initially, two measurements were performed for five minutes while the dust collector was turned on: (1) measurement of the acoustic noise level in the dust collector; (2) measurement of the vibration around the center of the dust collector.

Then, in order to discern the characteristics of the noise and vibration of the dust collector, the noise signals were recorded using both a microphone and vibration sensor simultaneously during the period of time at which the dust collector was running. In other words, recorded frequency and vibration frequency were compared by measuring vibrations and recording noise as a way to see whether major noise sources are created by vibration. The recording microphone and sound level meter were located at a distance of $30 \mathrm{~cm}$ horizontally, in the positions of A (Figure 4). Noise was analyzed by sampling the signal of the microphones with a frequency up to $44.1 \mathrm{kHz}$. A spectral analysis was performed using the Fast Fourier Transform (FFT) algorithm to identify dominant frequencies. The vibration, as well as the noise measurement, was realized by real-time recording of the signal using a vibration tester for five minutes during operation of the dust collector. The location of the vibration measurement positions was determined in the same manner as those of the noise measurement points. Vibration sensors were attached to the flat surface on the steel cover near the precipitator hoses at point A (see Figure 4) where the strongest vibration is triggered. 
Recording point $(A)$

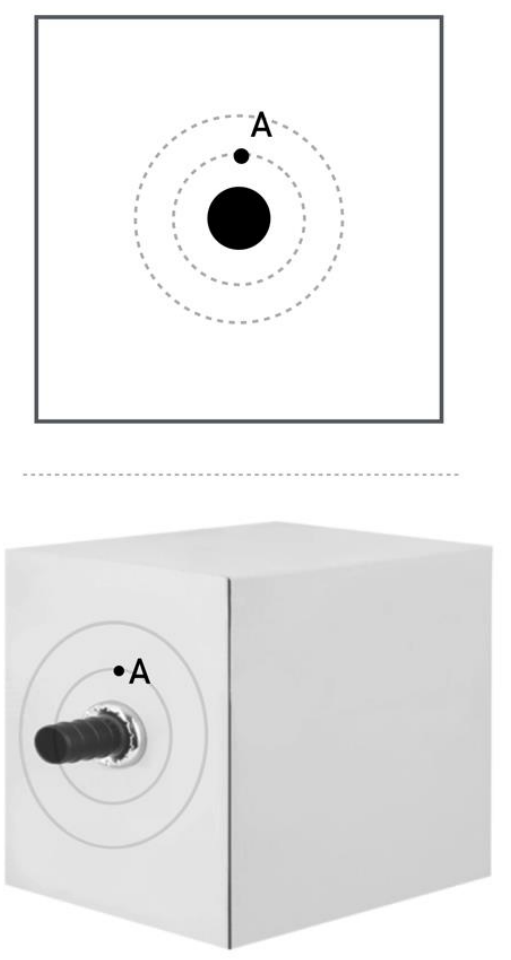

Figure 4. Dust collector noise level recording points.

\section{Experimental Result}

\subsection{Analysis of Noise Characteristics of Milling Machines}

Noise from milling machines was recorded as $80.2 \mathrm{~dB}(\mathrm{~A})$ on the front, $82.4 \mathrm{~dB}(\mathrm{~A})$ on the left, and $78.8 \mathrm{~dB}(\mathrm{~A})$ on the right when precipitators are used in the case of normal operation. When precipitators are not used, sound pressure on the front is $71.2 \mathrm{~dB}(\mathrm{~A}), 72.4 \mathrm{~dB}(\mathrm{~A})$ on the left, and $67.8 \mathrm{~dB}(\mathrm{~A})$ on the right. Table 3 shows sound pressures of milling machines and Figure 4 presents results as causes of generated noise and locations of major noise sources after investigating noise.

Table 3. Noise level of the milling machine using and not using a dust collector. SPL $=$ sound pressure level.

\begin{tabular}{cccc}
\hline Noise SPL (dB(A)) & Front & Left & Right \\
\hline $\begin{array}{c}\text { Not using dust } \\
\text { collector }\end{array}$ & 71.2 & 72.4 & 67.8 \\
Using dust collector & 80.2 & 82.5 & 78.8 \\
\hline
\end{tabular}

As shown in Table 3, the milling machine generates a louder noise when using a dust collector than when it was not used. Therefore, the use of a dust collector indicated the target noise of CAD/CAM machines. In this study, a focus was placed on the noise reduction of the dust collectors attached to milling machines.

\subsection{Analysis of Noise Characteristics of Dust Collectors}

Table 4 indicates that the vibration frequency at point $\mathrm{A}$ was $59.4 \mathrm{~Hz}$ when the noise from the dust collector was recorded and measured. It approached $60 \mathrm{~Hz}$ around the hose of the dust collector, which is where the center and the most powerful energy sound pressure level $(\mathrm{dB})$ was observed. Seeing that $60 \mathrm{~Hz}$ and the noise of harmonics accord with the number of revolutions of the compressor 
inside the dust collector in the bottom of the milling machine, it is supposed that the noise was generated because the vibration of the compressor was transmitted to the dust collector case.

Table 4. The sound pressure level of the dust collector at the recording point A.

\begin{tabular}{cc}
\hline Dust Collector & A \\
\hline Sound pressure level $(\mathrm{dB}(\mathrm{A}))$ & 82.5 \\
Vibration frequency $(\mathrm{Hz})$ & 59.4 \\
\hline
\end{tabular}

Figure 5 shows the power spectrum analyzed using data recorded around point $\mathrm{A}$, where the noise level of the dust collector is the highest. In this spectrum, frequency changes according to the length of the noise period, and it can be seen that the noise is generated at a constant level and concentrated in the frequency band of $60 \mathrm{~Hz}$. As a discrete tone, the noise of the dust collector has a fundamental frequency of nearly $60 \mathrm{~Hz}$ and a regular sound pressure variation to bring about the sense of pitch consisting of multiple harmonics. When it comes to frequency, this noise has a line spectrum (Figure 5).

It was found that the prominent band of the frequency spectrum obtained from the microphone and the main peak of the vibration frequency obtained from the vibration test coincided at about $60 \mathrm{~Hz}$. Based on these results, the vibration generated from the dust collector was confirmed as the main noise source. Vibration and noise generated from precipitators are considered as noise caused by vibration transferred from compressors. Generated causes, locations, and results can be analyzed as shown in Figure 6 depending on test results.

As a consequence of analysis of noise characteristics, the noise from the dust collector is caused by vibration transmitted from around the hose located on the side. The structure of the dust collector (see Figure 7) makes it difficult to add a noise reduction device (such as rubber/damper) inside.

Therefore, we propose a noise control method using anti-vibration as the most efficient method to reduce the undesired noise.
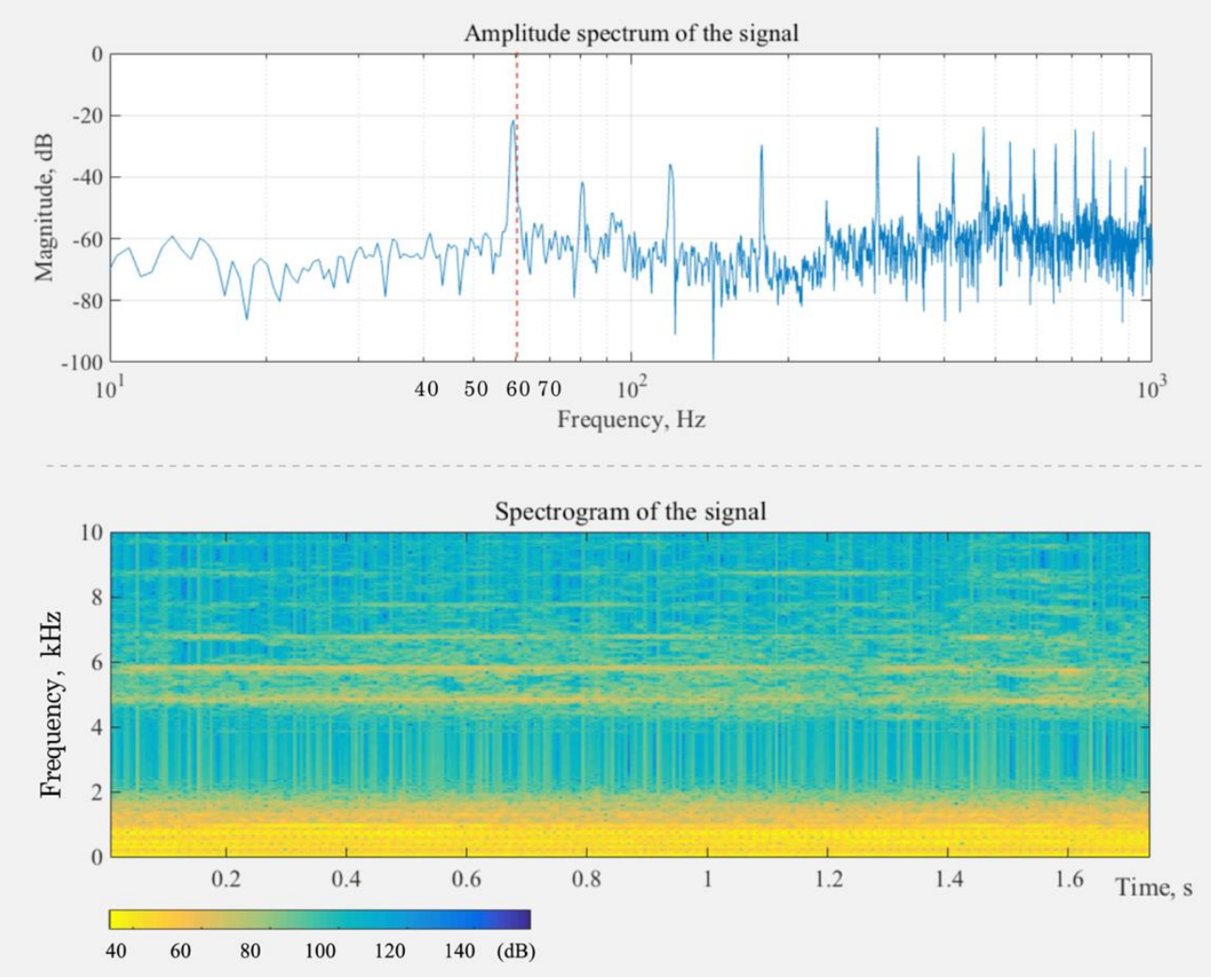

Figure 5. Frequency analysis and noise sound spectrum (linear scale). 


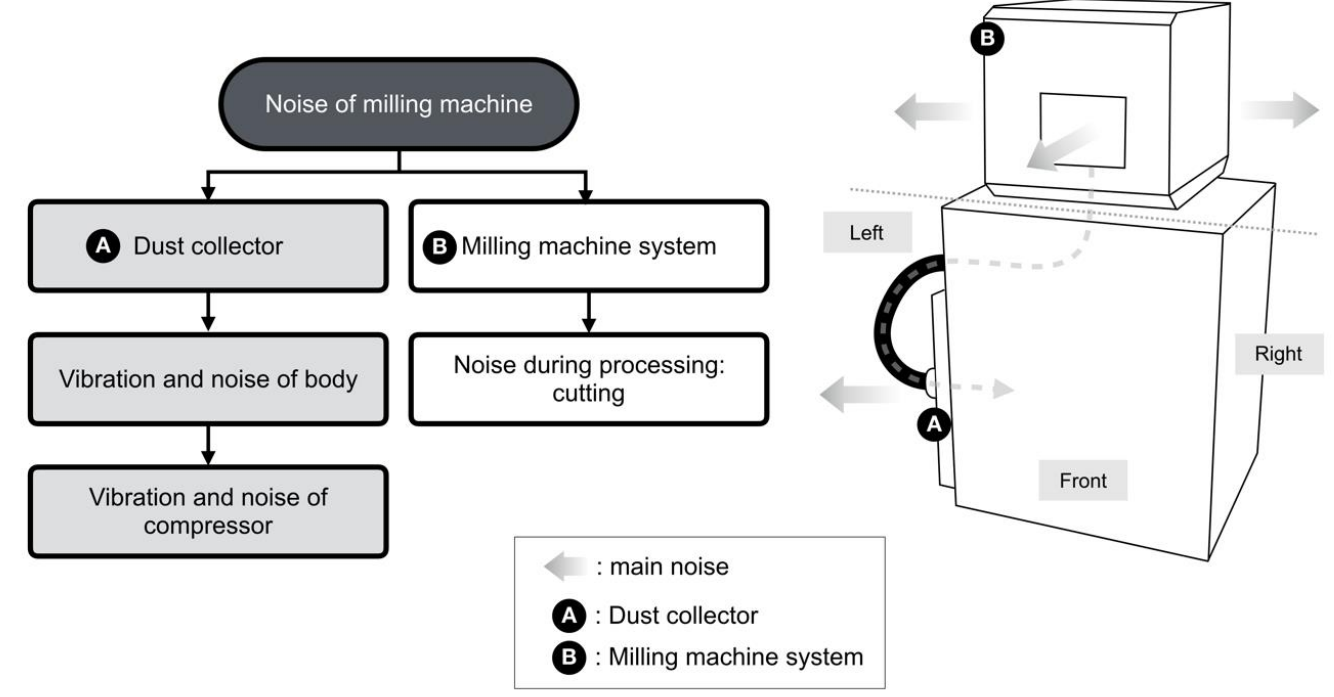

Figure 6. Identifying the main noise source of milling machines.

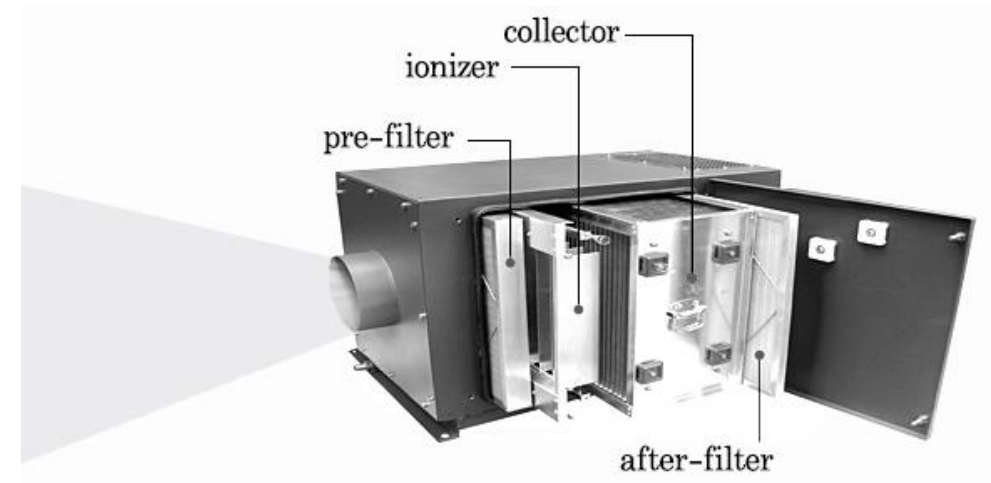

Figure 7. Internal structure of the dust collector.

\section{Noise Reduction Solution}

\section{Experimental Verification by Vibration Reduction Method}

A final set of experiments was conducted to measure the sound cancellation achieved through experimentation in a laboratory setting. In order to verify the validity of noise reduction through the vibration control method, a recording and noise measurement environment were constructed through a computer program. The program was created so that the noise reduction results could be analyzed after creating an experimental environment for vibration control using recorded noise files. Since the strongest vibration occurred around the hose area of the dust collector, the tactile transducer was attached to the area in which the strongest vibration (A) was generated to record the greatest sound pressure. A tactile transducer that was used in manufacturing the equipment and can generate vibration is also called a 'vibration speaker'. Based on the principle that in the domain of low frequency, it is possible to feel with one's body, not with one's ears, this speaker can transmit low-frequency vibration to the surface it is attached to, since this has no diaphragm.

In addition to the tactile transducer, a sensor was placed in the area in order to determine the vibrational frequency. The speaker reproduced a recorded sound source to simulate the vibration and noise generated by the dust collector. The tactile transducers reproduced anti-vibration with the sound of the same frequency and size emitted by the dust collector to control the vibration on the other side. The experimental set up is shown in Figure 8 and the noise control method and diagram are shown in Figures 9 and 10. 


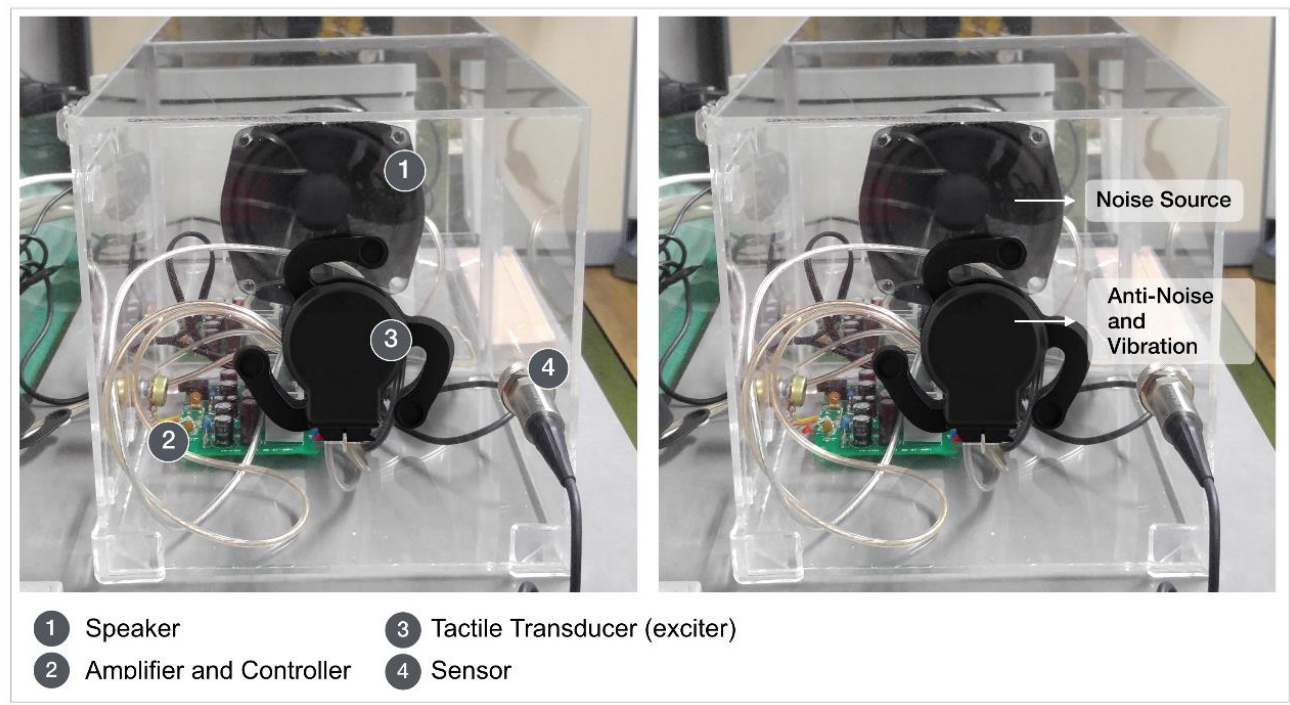

Figure 8. Experimental configuration.

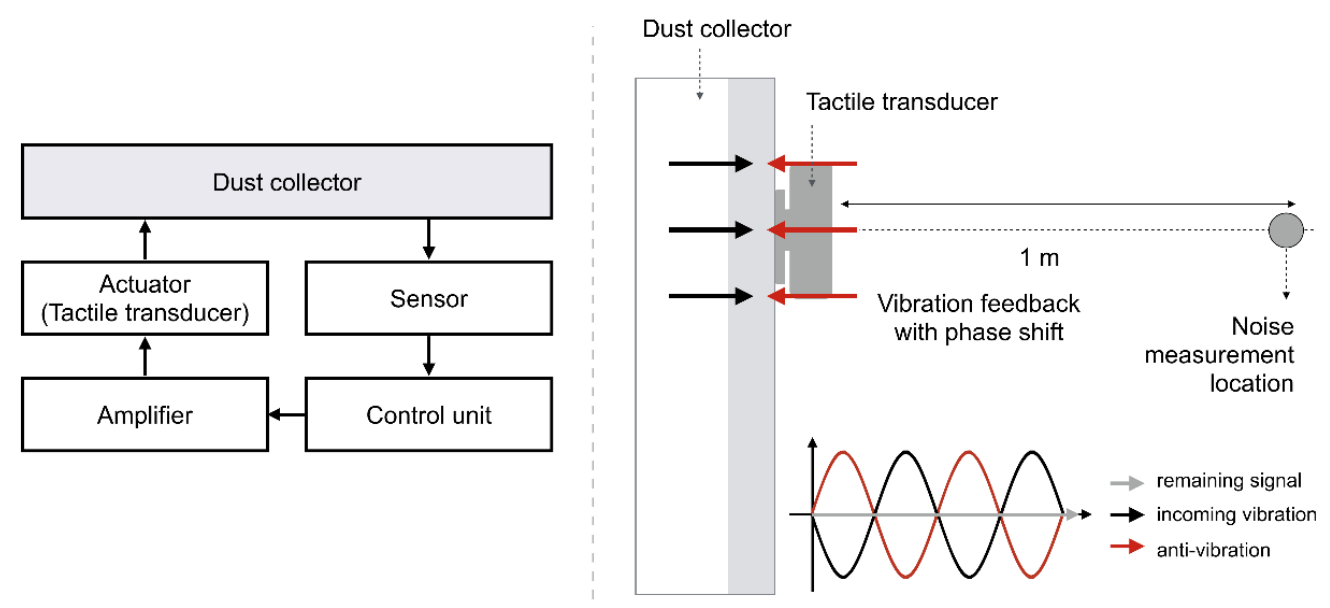

Figure 9. The diagram for the vibration reduction method.

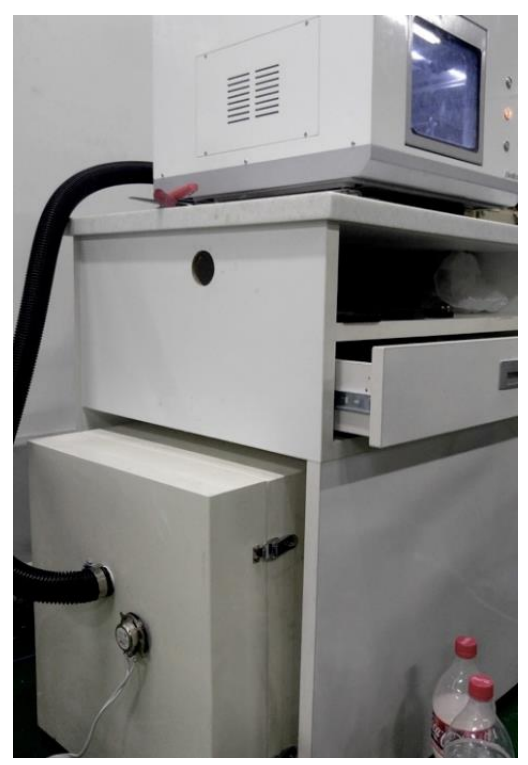

Figure 10. Vibration speaker installed at the dust collector. 
The result of the test demonstrated that it was possible to reduce the level of noise by only reducing vibration, because when the dust collector of the milling machine was used, vibration was transmitted to the surface of the dust collector by the compressor and the noise generated this time was dominant. Table 5 and Figure 11 indicate the result.

Table 5. Result values before and after.

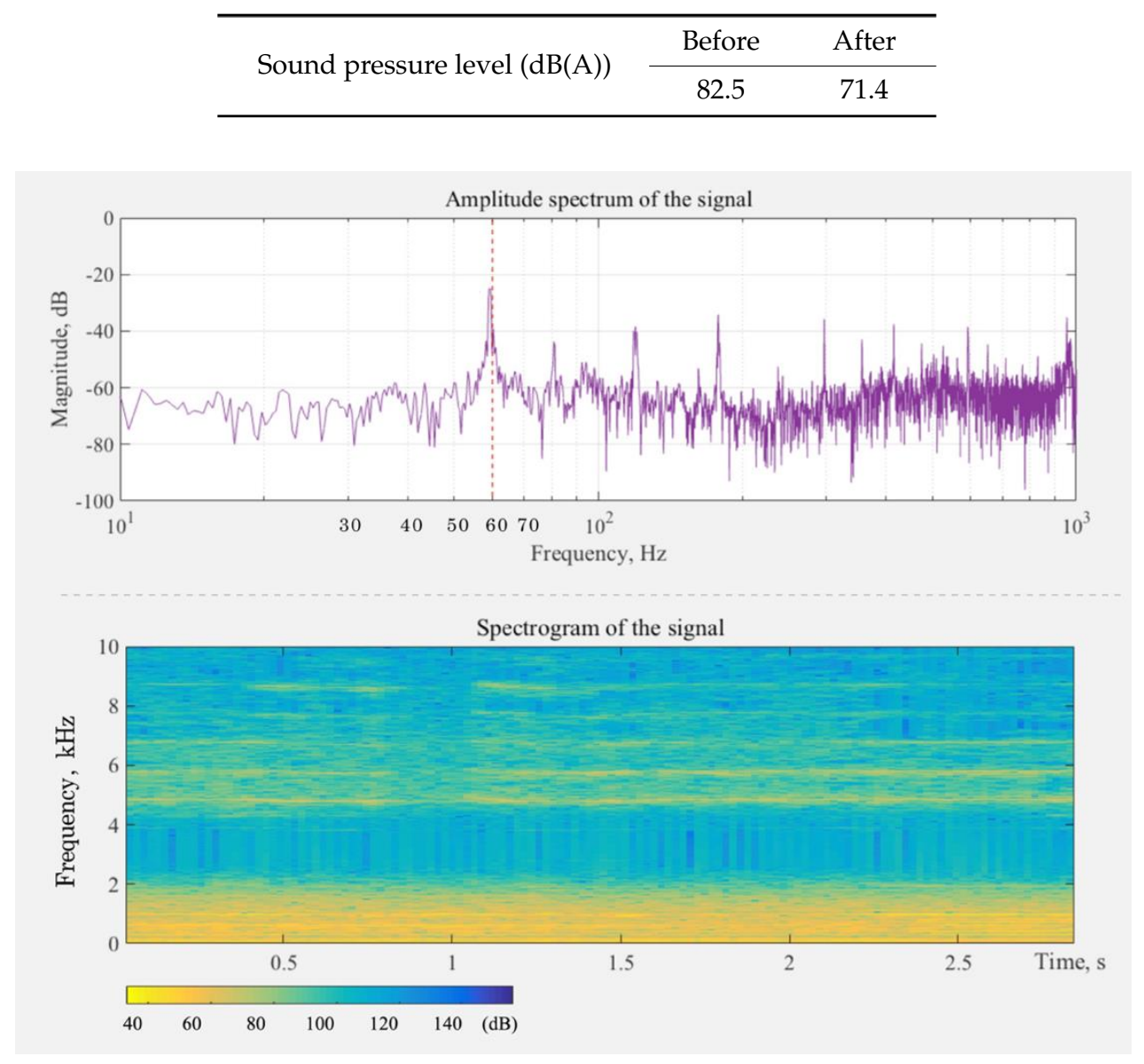

Figure 11. Result of noise reduction (frequency analysis and noise sound spectrum (linear scale)).

\section{Discussion}

For these experiments, noises produced from the milling machine varied according to the conditions of use: (1) types of materials used in processing, and (2) operation conditions (wet or dry). In Table 3 , the use of a dust collector for CAD/CAM milling produced the highest levels of noise-about $60 \mathrm{~Hz}$. Therefore, in this paper, a focus was placed on the noise analysis and reduction of the dust collectors attached to milling machines. The experiment indicated the results of the noise coming from the milling machine were being influenced by the vibrations of the dust collector.

As mentioned earlier, it seems that the noise is generated as vibration from the dust collector, which is then transmitted to the external case by the compressor inside the dust collector. It is anticipated that this can be applied not only to CAD/CAM milling machines for dental clinics but also to any machine using a dust collector and a compressor.

The key point in designing a successful controller is to first find the appropriate place for an actuator to be set. Second, the type of available and accessible sensors and actuators should be specified. In this paper, we have chosen an electro-mechanic transducer called an exciter (also called a tactile transducer) as an actuator. The exciter is normally a moving coil device, which is carefully positioned and designed to optimally excite the natural resonant modal structure of the panel [16]. 
Tactile transducers create and transmit low frequency vibrations to create tactile sound. Tactile sound is present in the vibratory signature of musical instruments, automobiles, aircrafts, and refrigerator compressors $[17,18]$. In addition, when a sound is generated by a tactile transducer, it performs a linear motion and can create strong vibrations (see Figure 12). As an actuator of a linear motor type speaker, tactile transducers are able to control vibrations by sound with ease and accuracy. In addition, linear actuators, in contrast to electric motors, are able to deliver energy not only in the form of vibrations, but also in the form of actual motion. The use of the tactile transducer (vibration speaker or exciter) makes it possible to generate vibration without designing a complex structure for vibration reduction. Besides, this can be applied to various devices and is very efficient to control and in reducing the cost.

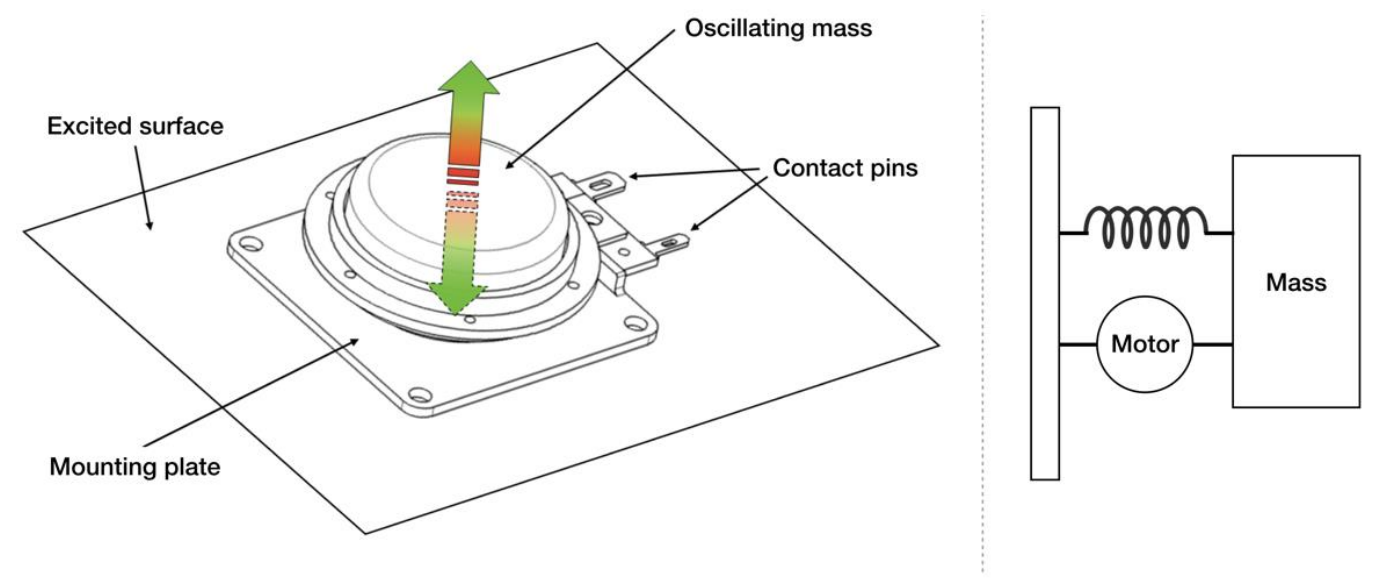

Figure 12. Voice coil type tactile transducer and basic principles of exciter technology.

Noise in the dental practice setting causes an unpleasant experience [19]. As shown in the study by Lee et al. [20], the highest dental practice noise level at the distance of $100 \mathrm{~cm}$ is $77 \mathrm{~dB}$, and $82.5 \mathrm{~dB}$ for milling machines. This suggests that the emergence of milling machines may cause a louder noise, which calls for attention. It was revealed that in this study, the noise reduction plan using the vibration reduction method can be effectively applied to the noise characteristics of the milling machine. However, the internal and external noises, including events while systems are on or off, were not considered in the present experiment. It is, therefore, thought that additional measures for reducing the noise caused by unpredictable and uncertain events would be needed. In addition, the quality and characteristics of the remaining sound after control were not evaluated. Therefore, the proposed method in this paper does not fully specify a solution to this issue.

In many practical active noise control applications, the undesired primary noise consists of multiple harmonic-related tones, which can be effectively reduced by internal model control feedback ANC systems [21]. In this study, we also created a simulated environment using tactile transducers and sensors to confirm our prediction of the effectiveness of anti-vibrations in decreasing sound pressure levels. However, our experiment did not completely cover significant aspects, which must have been taken into account if experimentation had been done with real-time milling machine vibrations. In order to resolve real-time noise levels, a feedback system should be established, which would be able to consider factors such as the material, type of milling, and model type.

In addition, it is necessary to use additional sensors and identify the optimal algorithm to reduce noise errors and in response to unexpected noise. Further research could focus on an in depth analysis of the quality and characteristics needed in future studies after the removal of sound.

Furthermore, additional studies that could be done could focus on the improvement of clinical noise levels in terms of sound quality and control. Our experiment indicated a decrease in noise levels. However, determination of sound frequency disruptiveness varies from person to person, causing subjectivity. To alleviate this issue, surveys and further research must be done to identify the types of noises at which dental clinicians and patients find the most discomfort. 


\section{Conclusions}

The noise generated by CAD/CAM milling machine operation was reduced by $9 \mathrm{~dB}$ using the proposed vibration control method. The noise intensities and frequencies of the milling machines were mainly characterized by low frequency range vibrations (about $60 \mathrm{~Hz}$ ) coming from the dust collector. Our method significantly decreased noise levels in order to create a better clinical environment for both dental professionals and patients. Further research could be done on not only identifying and decreasing the intensity of noise, but also evaluating the quality and characteristics of the noise on the qualitative level and developing a feedback system.

Author Contributions: Conceptualization, E.-S.S.; methodology, Y.-J.L.; software, E.-S.S.; validation, B.K.; investigation, B.K.; data curation, E.-S.S. and B.K.; writing-original draft preparation, E.-S.S.; writing-review and editing, Y.-J.L. and J.S.M.; visualization, E.-S.S.; supervision, Y.-J.L.

Funding: This work was supported by grant no. 04-2017-0092 from the Seoul National University Dental Hospital Research Fund, Seoul National University Dental Hospital. The APC was funded by “Dental Research Institute, School of Dentistry, Seoul National University, Seoul, Republic of Korea".

Conflicts of Interest: The authors declare no conflict of interest.

\section{References}

1. Khaimook, W.; Suksamae, P.; Choosong, T.; Chayarpham, S.; Tantisarasart, R. The prevalence of noise-induced occupational hearing loss in dentistry personnel. Workplace Health Saf. 2014, 62, 357-360. [CrossRef] [PubMed]

2. Ahmed, H.O.; Ali, W.J. Noise levels, noise annoyance, and hearing-related problems in a dental college. Arch. Environ. Occup. Health 2017, 72, 159-165. [CrossRef] [PubMed]

3. Theodoroff, S.M.; Folmer, R.L. Hearing loss associated with long-term exposure to high-speed dental handpieces. Gen. Dent. 2015, 63, 71-76. [PubMed]

4. Gijbels, F.; Jacobs, R.; Princen, K.; Nackaerts, O.; Debruyne, F. Potential occupational health problems for dentists in Flanders, Belgium. Clin. Oral Investig. 2006, 10, 8-17. [CrossRef] [PubMed]

5. Messano, G.A.; Petti, S. General dental practitioners and hearing impairment. J. Dent. 2012, 40, 821-828. [CrossRef] [PubMed]

6. Kuo, S.M.; Morgan, D.R. Active Noise Control Systems: Algorithms and DSP Implementations, 1st ed.; Wiley: New York, NY, USA, 1996.

7. Kuo, S.M.; Chen, Y.-R.; Chang, C.-Y.; Lai, C.-W. Development and Evaluation of Light-Weight Active Noise Cancellation Earphones. Appl. Sci. 2018, 8, 1178. [CrossRef]

8. Beranek, L.L. Noise and Vibration Control Engineering: Principles and Applications, 2nd ed.; Wiley: New York, NY, USA, 2006; pp. 721-855.

9. Gan, W.S.; Mitra, S.; Kuo, S.M. Adaptive feedback active noise control headset: Implementation, evaluation and its extensions. IEEE Trans. Consum. Electron. 2005, 51, 975-982. [CrossRef]

10. Vu, H.S.; Chen, K.H. A low-power broad-bandwidth noise cancellation VLSI circuit design for in-ear headphones. IEEE Trans. Very Large Scale Integr. (VLSI) Syst. 2016, 24, 2013-2025. [CrossRef]

11. Guldenschuh, M.; de Callafon, R. Detection of secondary-path irregularities in active noise control headphones. IEEE/ACM Trans. Audio Speech Lang. Process. 2014, 22, 1148-1157. [CrossRef]

12. Chang, C.Y.; Li, S.T. Active noise control in headsets by using a low-cost microcontroller. IEEE Trans. Ind. Electron. 2011, 58, 1936-1942. [CrossRef]

13. Lim, D.H.; Kim, M.; Park, H.M. Active noise canceling for headphones using a hybrid structure with wind detection and flexible independent component analysis. IEICE Trans. Inf. Syst. 2015, E98D, 2043-2046. [CrossRef]

14. Kuo, S.M.; Mitra, S.; Gan, W.S. Active noise control system for headphone applications. IEEE Trans. Control Syst. Technol. 2006, 14, 331-335. [CrossRef]

15. Pleban, D. Definition and measure of the Sound Quality of the machine. Arch. Acoust. 2014, 39, 17-23. [CrossRef]

16. Lopez, J.J.; Cobos, M.; Pueo, B. Conventional and distributed mode loudspeaker arrays for the application of wave-field synthesis to videoconference. In Proceedings of the 11th International Workshop on Acoustic Echo and Noise Control, Seattle, WA, USA, 14-17 September 2008. 
17. Marshall, M.T.; Wanderley, M.M. Vibrotactile Feedback in Digital Musical Instruments. In Proceedings of the 2006 International Conference on New Interfaces for Musical Expression, Paris, France, 4-8 June 2006; pp. 226-229, ISBN 2-84426-314-3.

18. Pietila, G.; Cerrato, G. Sound Quality Guidelines for Non-Automotive Products. Sound Vib. 2012, 8-14.

19. Muppa, R.; Bhupatiraju, P.; Duddu, M.; Penumatsa, N.V.; Dandempally, A.; Panthula, P. Comparison of anxiety levels associated with noise in the dental clinic among children of age group 6-15 years. Noise Health 2013, 15, 190-193. [CrossRef] [PubMed]

20. Lee, J.S.; Han, Y.S.; Cho, Y.S. The Noise Level Assessment of Dental Equipment. J. Dent. Hyg. Sci. 2015, 15, 603-611. [CrossRef]

21. Wang, T.; Gan, W.; Kuo, S.M. New feedback active noise control system with improved performance. In Proceedings of the IEEE International Conference on Acoustics, Speech and Signal Processing (ICASSP), Florence, Italy, 4-9 May 2014; pp. 6662-6666. [CrossRef]

C 2019 by the authors. Licensee MDPI, Basel, Switzerland. This article is an open access article distributed under the terms and conditions of the Creative Commons Attribution (CC BY) license (http://creativecommons.org/licenses/by/4.0/). 